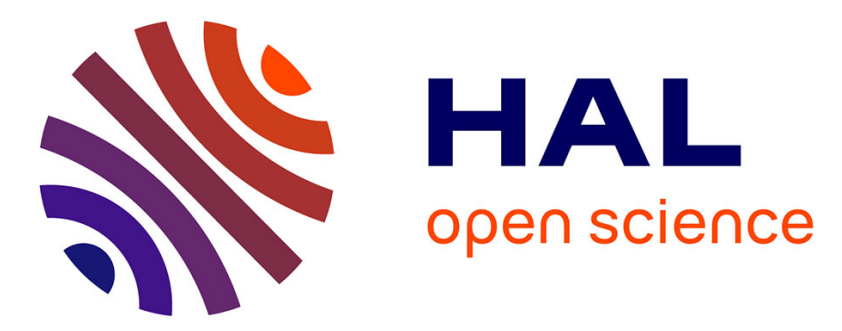

\title{
Compact module for high power coherent beam combining of tapered amplifiers
}

J. Hamperl, P. Albrodt, Patrick Georges, Gaëlle Lucas-Leclin

\section{To cite this version:}

J. Hamperl, P. Albrodt, Patrick Georges, Gaëlle Lucas-Leclin. Compact module for high power coherent beam combining of tapered amplifiers. 2019 IEEE High Power Diode Lasers and Systems Conference (HPD), Oct 2019, Coventry, United Kingdom. pp.33-34, 10.1109/HPD48113.2019.8938676 . hal-03109319

\section{HAL Id: hal-03109319 https://hal.science/hal-03109319}

Submitted on 13 Jan 2021

HAL is a multi-disciplinary open access archive for the deposit and dissemination of scientific research documents, whether they are published or not. The documents may come from teaching and research institutions in France or abroad, or from public or private research centers.
L'archive ouverte pluridisciplinaire HAL, est destinée au dépôt et à la diffusion de documents scientifiques de niveau recherche, publiés ou non, émanant des établissements d'enseignement et de recherche français ou étrangers, des laboratoires publics ou privés. 


\title{
Compact module for high power coherent beam combining of tapered amplifiers
}

\author{
J. Hamperl ${ }^{1}$, P. Albrodt ${ }^{1}$, P. Georges ${ }^{1}$ and G. Lucas-Leclin ${ }^{1 *}$, \\ ${ }^{1}$ Laboratoire Charles Fabry, Institut d'Optique Graduate School, CNRS, Université Paris-Saclay, \\ 2 Avenue Augustin-Fresnel, 91127 Palaiseau, France (" gaelle.lucas-leclin@institutoptique.fr)
}

\begin{abstract}
We describe the design and evaluation of a small footprint interferometer for the coherent beam combining of highbrightness semiconductor amplifiers. The setup relies on off-theshelf commercial devices only. The combined output power reaches $9.7 \mathrm{~W}$ in a nearly diffraction-limited beam.
\end{abstract}

Index Terms - Semiconductor optical amplifiers, Optical interferometry, Phase measurement.

\section{INTRODUCTION}

$\mathrm{H}$ IGH power laser systems with good beam quality are in great demand in many different fields of research and industry. The wavelength diversity, their intrinsic compactness and ease of use are clear advantages of semiconductor lasers. However, the output power from single-mode semiconductor emitters is limited by thermal effects and damage thresholds. Coherent beam combining (CBC) is a successful concept to increase the power of a laser system while maintaining its beam quality, thus scaling its brightness [1]. It relies on the coherent superposition of multiple beams with identical spectra by constructive interference. This approach was demonstrated with semiconductor amplifiers in different architectures [2-4] but with specifically designed devices only. We describe here a coherent combining prototype featuring four commercially available high-brightness tapered amplifiers in a master oscillator power amplifier configuration following our previous work with high performance tapered amplifiers [4].

\section{Description OF THE COMPaCt CBC MOdUle}

The CBC module was a typical four-arm Mach-Zehnder interferometer, which consisted of two independent submodules with two amplifiers each (Fig. 1). The master oscillator (MO) was a narrow linewidth DBR laser diode (Photodigm PH976280TO, $\lambda=976 \mathrm{~nm}$ ) delivering up to $280 \mathrm{~mW}$ in a freespace single-mode beam. A double stage isolator $(>50 \mathrm{~dB}$ isolation) was used to avoid feedback from the amplifiers that might destabilize the MO line. The beam was split and recombined by a series of standard nonpolarising 50:50 plate beam splitters. Each amplifier was seeded with $30 \mathrm{~mW}$.

The power amplifiers (PA) were commercially available $5 \mathrm{~mm}$ long tapered amplifiers for the spectral range of $960 \mathrm{~nm}$ to $985 \mathrm{~nm}$ (DILAS TA-0976-3000). The amplifiers were mounted p-side down on a DHP-inset packaging that ensures a good heat evacuation. The ridge and the tapered sections shared the same electrical contact. The optical power extracted from each amplifier was above $3 \mathrm{~W}$ at 5 A. Each PA output beam was separately collimated in the fast and slow axes with an aspheric lens and an acylindrical lens glued on the submodules with a UV curing adhesive. The setup was optimized for operation at the maximum current of $5 \mathrm{~A}$ per amplifier. The $\mathrm{M}^{2}$ beam propagation factors were measured following the ISOstandard-compliant $4 \sigma$ method. The $\mathrm{M}^{2}$ of the PA (at I $=5 \mathrm{~A}$ ) ranged from 2.1 to 2.7 in fast axis (FA) and from 5.0 to 6.5 in slow axis (SA) [5].
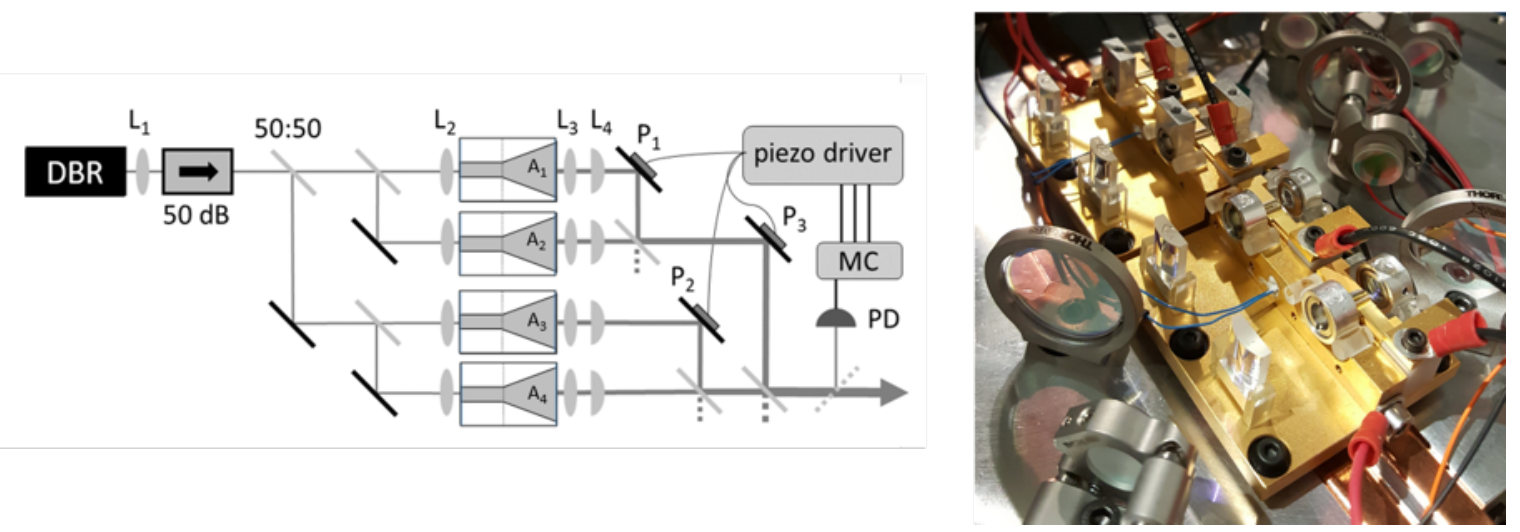

Fig. 1 (left) Simplified schematic of the experimental setup. (right) Photograph of the assembled CBC module. 
The amplifiers were mounted two by two on a common thermally-stabilized copper baseplate in order to limit their relative phase fluctuations. The collimated output beams were recombined with 50:50 beam splitters. We used three folding mirrors glued on piezoelectric chips for controlling the relative piston phases in the interferometer. The frequency bandwidth of the piezo-mirror arrangement was experimentally evaluated to $6.6 \mathrm{kHz}$. This was far above the bandwidth of the relative phase fluctuations between amplifiers, which is typically below $100 \mathrm{~Hz}[5]$.

A fraction of the combined output beam was measured with a photodiode which provided the error signal. The active control loop was based on a sequential hill-climbing algorithm with adaptative steps implemented in a microcontroller, which controlled the piezo-drivers.

\section{Evaluation}

The combined power, combining efficiency and beam quality of the combined beam was measured for both submodules individually (see Fig. 2). For submodule 1, the coherent superposition of amplifiers $A_{1}$ and $A_{2}$ resulted in an output power of roughly $6.2 \mathrm{~W}$ with a combining efficiency of $84 \%$. The performance of submodule 2 was slightly inferior with $5.8 \mathrm{~W}$ combined power and a combining efficiency of $80 \%$ The highest combined output power resulting from the coherent superposition of the two submodules was $9.7 \mathrm{~W}$. The overall

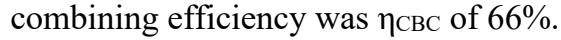

The coherent superposition of the imperfect amplified beams leads to a clean-up of the spatial profiles at each combining stage. This is evidenced in Fig. 2 by the improvement of the power content in the central lobe $\gamma_{\mathrm{cl}}$, which increases from $70 \%$ - $75 \%$ for the individual amplified beams to $85 \%$ for the final combined beam. Indeed residual high-order modes in each beam are mismatched and do not interfere efficiently on the combining element contrary to the central lobes. Side-lobes in the final combined beam were less pronounced. The resulting beam quality factors were improved to 1.8 and 2.7 in FA and $\mathrm{SA}$ respectively. The power content in high-order modes of the PA output beams was the strongest limitation to the combining efficiency in our setup.

The stability of the coherent beam over 160 min was measured (see Fig. 3). The average combined power at the output of the interferometer was $9.5 \mathrm{~W}$, with a RMS stability better than $0.6 \%$. The amplitude of the corrections applied to the piezoelectric elements P1 and P2 (respectively for the coherent superposition on each submodule) was below $1 \mathrm{~V}$ during the whole measurement, which corresponds to phase fluctuations smaller than $0.5 \pi$ (Fig. 3 (b)). As expected the phase fluctuations between the two submodules, corrected by P3, were slightly higher.

\section{CONCLUSION}

We demonstrated the development of small footprint modules of coherently combined tapered amplifiers based on off-the-shelf elements only. The setup is particular simple and can easily be transferred to other wavelengths. The output power of $9.7 \mathrm{~W}$ is roughly three times higher than the typical maximum power of commercially available tapered amplifiers and at the same time we significantly improved the beam quality Such modules could significantly improve the performance of laser systems relying on tapered amplifiers for applications such as spectroscopy or atom cooling. Furthermore, CBC modules might also be an excellent high brightness pump source for solid-state lasers or nonlinear frequency conversion.

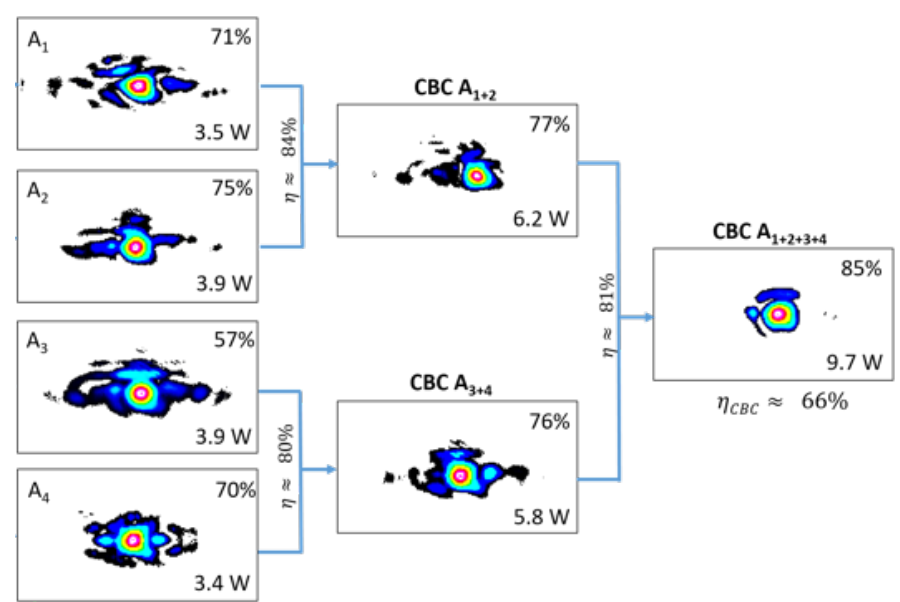

Fig. 2. Beam profiles at waist of single amplifiers and the beams after coherent superposition. Each amplifier is operated at a current of $5 \mathrm{~A}$. Percentage in top right corner indicates the estimated central lobe power content of each beam. $\eta$ denotes the combining efficiency at each stage and $\eta_{\mathrm{CBC}}$ is the overall combining efficiency. FA is in vertical, SA is in horizontal direction.

(a)

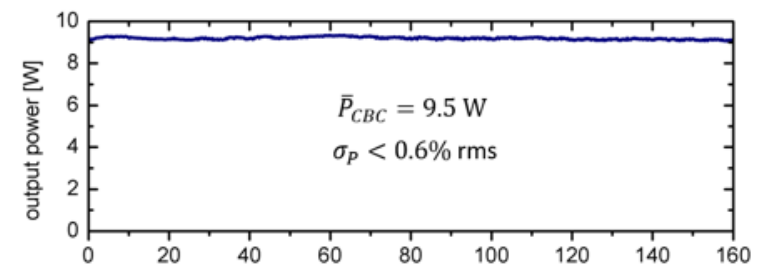

(b)

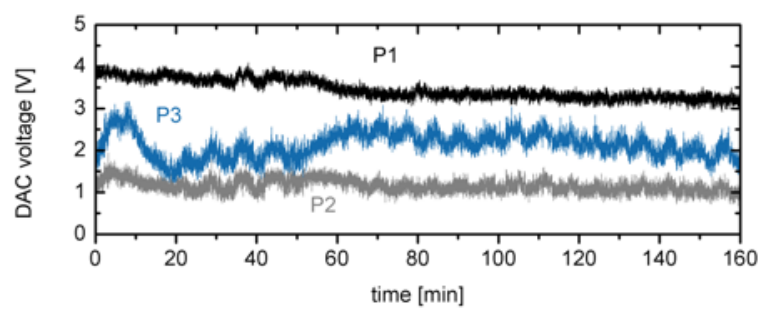

Fig. 3. (a) Power stability of the coherently combined beam over $160 \mathrm{~min}$. (b) Signals sent by the microcontroller to the piezo driver. A change of about $2 \mathrm{~V}$ corresponds to a phase shift of $\pi$.

\section{REFERENCES}

[1] T. Y. Fan, "Laser Beam Combining for High-Power, High-Radiance Sources," IEEE J. Sel. Top. Quant. Electron. vol. 11, no. 3, pp. 567-577, 2005.

[2] K. J. Creedon et al., "High efficiency coherent beam combining of semiconductor optical amplifiers," Opt. Lett., vol. 37, no. 23, pp. 5006$5008,2012$.

[3] G. Schimmel et al., "Coherent beam combining architectures for high power tapered laser arrays," in Proc. SPIE 10086, pp. 10086-22, 2017.

[4] P. Albrodt et al., "Coherent superposition of pulsed high-brightness tapered amplifiers," in Opt. Express, vol. 27, no. 20, 2019.

[5] J. Hamperl, "Coherent combining of high-brightness tapered semiconductor amplifiers", Master thesis, Friedrich-Schiller-Universität Jena, 2019. 